\title{
Undernutrition, Food Insecurity and Associated Factors among Adult HIV Positive people on HAART in Public Health Facility in Oromia Special Zone Surrounding Finfinne, Oromia, Ethiopia.
}

Desalegn Neme ( $\sim$ desalegnneme2021@gmail.com )

Haile Bikila

Wollega University

Tariku Tesfaye

Wollega University

Markos Desalegn

Wollega University

Zalalem Kaba

Research Article

Keywords: malnutrition, Human Immunodeficiency virus (PLHIV), food insecurity, Ethiopia

Posted Date: September 21st, 2021

DOI: https://doi.org/10.21203/rs.3.rs-815780/v1

License: (c) (i) This work is licensed under a Creative Commons Attribution 4.0 International License.

Read Full License 


\section{Abstract}

Background: Malnutrition is resulted from inequalities in nutrients intake and body demands. People living with Human Immunodeficiency virus (PLHIV) are more vulnerable to malnutrition, due to opportunistic infection, metabolic disorder, and increased need of energy during infection. Worldwide, over 800 million people are chronically undernourished. The dual burden in areas of severe food insecurity and Human Immunodeficiency virus (HIV) epidemic are highly contributing to morbidity and mortality of people living with HIV, especially in developing countries particularly Sab-Saharan Africa is considered as home of malnutrition and food insecurity. The major problem of PLHIV in Ethiopia is under nutrition and its complication.

Objective: This study aimed to assess magnitude of under nutrition, food insecurity and associated factors among adult clients on ART attending ART clinic, at public health facilities, Oromia regional states central Ethiopia

Method: An institution based cross-sectional study was conducted among adult PLHIV and on highly active antiretroviral therapy(HAART) attending public health facility in Oromia Special Zone Surrounding Finfinne (OSZSF) was conducted from August 2020 to May 2021. A systematic sampling was applied for sample selection. A pre tested semi structured questionnaire was used to collect data. Bivariate and multivariable analysis also employed to identify the presence, strength, direction of association and other confounding. After calculating for both first objective (prevalence of under nutrition) and second objective or factors associated with under nutrition the maximum sample size 305 was selected for this study.

Result: The prevalence of under nutrition was $22.4 \%$ and house hold food insecurity was also high in current study $54.3 \%$. Factors associated with under nutrition among participants were absence of ration (AOR=0.42, 95\% Cl: 0.0-0.9), World health organization clinical stage II, III and VI (AOR= 6.8, 95\%Cl: 2.5 18.6) and household food in secure $(A O R=0.51,95 \% \mathrm{Cl}: 0.27-0.95)$ while literacy status primary and less $(A O R=2.24,95 \% \mathrm{Cl}: 1.1-4.6)$, household average monthly income $<2250$ Ethiopian birr (AOR=0.41, $95 \% \mathrm{Cl}: 0.21-0.8)$ and meal frequency less or equal to two (AOR=4.14, 95\%Cl:1.3-13.46).

Conclusion and recommendation: This study finding reveals high prevalence of under nutrition and $\mathrm{HH}$ food insecurity results in disturbing the success of the program, thus Comprehensive care and support bio-medical and inter-sectorial collaboration is suggested for alleviating the problem.

\section{Background}

Malnutrition is the state of diminished physical functioning of individual and can no more maintaining the body's performance process of productive life (growth, pregnancy, physical activity, recovering from disease)[1]and resulted from inequality in intake and body require of food or nutrients for productive life of individuals for growth, maintenance, regulation and reproduction[2]. People living with human immunodeficiency virus (PLHIV), due to opportunistic infection, food mal-absorption, anorexia and 
increased nutritional demand; are most vulnerable to malnutrition. The increased need of additional food during infection is other problem for PLHIV [3].

Worldwide over 800 million people were constantly undernourished; the areas of already suffering from food insecurity and HIV epidemic overlaps that contributing for morbidity and mortality in developing countries[4,5,6]. Severe food insecurity and undernourishment increased in Africa and South America while stable in most regions of Asia [4, 5]. More than $56 \%$ of African-American women living with HIV on highly active antiretroviral therapy (HAART) in rural Alabama, USA were categorized as food insecure [7].

Sab-Saharan countries are considered as the home of malnutrition and food insecurity sharing majority of the world's undernutrition and food insecure population. Poor infrastructure, restricted or limited resource, conflict, HIV and low access to health service are worsening the condition [8]. Undernutrition and nutrition related complications are one of the major challenges in Ethiopia among HIV positive reproductive age groups in achieving ART intervention. Currently; around $20 \%$ and $17 \%$ reproductive age HIV positive women are chronically undernourished and anemic respectively [9]. And there is also high prevalence of food insecurity among adult PLHIV attending ART clinic; at Butajira Hospital (78.1\%)[10], in Kenbata Tembaro zone health facilities providing ART service were (57.3\%)[11] and at Fitche Hospital 341 (87.4\%) were food insecure[12]. Ethiopia provides nutritional support integrating in comprehensive HIV treatment, care and supports addressing food in security and under nutrition through financial, food and income generating activity (IGA) support. In spite of this, there is high gap between interventions on nutrition and the desired outcome of nutritional status.

HIV affects the nutritional status both directly and indirectly. Direct effects are increased energy requirement, reduced food intake and poor nutrient absorptions. Negative effect of HIV indirectly, weakens immune system, illness and health care cost; Leads in to malnutrition [13, 14, 15]. Malnutrition, food insecurity and HIV are complexly related and worsen the negative impacts of one another. Food insecurity has a negative impact on the overall nutritional and health status of those infected and affected by HIV/AIDS, and people living with HIV often express that food is the greatest need for themselves and their families [8]. And malnutrition can be a contributor and outcome of HIV progress. Malnourished HIV infected individual's progresses to AIDS faster [16].

Food insecurity is both the problem of developed and developing countries even if high in developing countries. By 2017 USAIDs Economic research service reports 15.0 million households (11.8\%) in America were under food insecure [17]. About 49 million Americans were food insecure and $67.6 \%$ of individuals are adult [6].

Common problems in HIV infected people regarding nutritional status are weight loss due to dietary intake (anorexia, mouth ulcer, and food insecurity), mal-absorption and altered metabolism. Improving from weight loss and predominantly muscle mass; needs ART, treatment of Ol, consumption of balanced diet, appetite stimulants and growth hormone. This is difficult in resource limited region and problematic if the infection is highly advanced [18]. 
High prevalence of malnutrition exacerbates the outcome of HIV and poses significant challenges to HIV care and treatment program in Ethiopia [19]. In Ethiopia currently around $26 \%$ of adults PLWHIV on ART follow up were undernourished [20]. A study conducted among adult clients attending ART clinic at public health facilities indicate that current cigarette smokers, those at WHO stage four and three those who consume less than five food groups are at risk of getting under nutrition [19,21]. Other risks of malnutrition in people living with HIV receiving ART at organization for social health development in ArbaMinchi and Jimma town are low monthly income, educational status and advancement of HIV that increases the prevalence of under nutrition [21,22]. The report indicates that $43 \%$ of them are malnourished during the early initiation of antiretroviral therapy [22]. Also HIV and food insecurity can be a significant catalyst result of one another [23].

Regardless of complex interaction between HIV, malnutrition and food insecurity many studies identify the burden of under nutrition and food insecurity separately on adult HIV positive people on ART. Then, this study identified the magnitude of under nutrition, household food insecurity and risk factors affecting the nutritional status and household food in security of PLHIV in detail and their collective negative outcomes.

Fig.1:- Conceptual Framework on food insecurity, under-nutrition and associated factors among PLWHIV on ART follow-up.

\section{Methods And Materials}

\subsection{Study area and Period}

The study was conducted in public health institutions providing antiretroviral therapy service in Oromia Special Zone surrounding Finfinne. Oromia Special Zone is found in Addis Ababa and the health facilities in which the study was conducted are found $30 \mathrm{KM}$ to $72 \mathrm{Kms}$ away from the Addis Ababa in all direction. The Zone is established in 2014 and has 6 Woredas, one town administrative and 68 Kebeles (the smallest administrative unit in Ethiopia) structures. There are 28 public health institutions (2 primary hospitals and 28 health centers). Out of these; 9 of them are providing ART service. No private health facility providing ART service within the Zone. There are 2,440 paediatric and adult PLHIV currently on ART in the Zone. The study was conducted from August 13, 2020 to May, 2021.

\subsection{Study Design}

- An institution based cross-sectional study was conducted among adults PLHIV on HAART.

\subsection{Population}

\subsubsection{Source Population}


- All adult PLWHA ( $\geq 18$ years old) and on HAART in health institutions providing ART service in OSZSF, Oromia, Ethiopia were taken as the source population.

\subsubsection{Study Population}

- All adult PLWHA ( $\geq 18$ years of age) on HAART who were attending ART clinic at the study public health facility during data collection period were taken as the study population.

\subsection{Eligibility criteria}

\subsubsection{Inclusion criteria}

- All study participants whose age was $\geq 18$ years of age on HAART for more than three months were included in the study.

\subsubsection{Exclusion criteria}

- Severely or unable to respond and mentally ill PLWHA on screening and those who was not be volunteer to participate on the study was excluded.

- Pregnant and lactating mother those who were on PMTCT were excluded because of pregnancy and lactation increases the vulnerability of malnutrition.

\subsection{Sample size and Sampling technique}

\subsubsection{Sample size}

The sample size was calculated using a single population proportion formula, taking the similar characteristic population, prevalence of under nutrition $23.6 \%$ based on study done in West Shewa zone among adult PLWHA attending ART clinic [24].

- $D=$ Margin of error of $5 \%, Z a / 2=1.96$ or $95 \%$ Confidence level:-

$$
\mathbf{n}=\left(\frac{Z \alpha}{2}\right) 2 \frac{P(1-p)}{D 2} \quad \mathbf{n}=(1.96) 2 \frac{0.236(1-0.236)}{(0.05) 2}
$$

$\mathrm{n}=3.84 \frac{0.18}{0.0025}=277$. Adding a $10 \%$ possible non response rate, the total calculated sample size required was 305 . To determine the required sample size for the second objective, different significantly associated with under nutrition variables were considered with the assumption of confidence level $95 \%$, power $80 \%$ and odds ratio for each factor and $10 \%$ non-response rate using El info version 7.2.1 was 
used. After calculating the required sample size for those selected variables, the maximum sample was used by comparing both objectives. Accordingly, the maximum sample used for this study was the first objective 305[Table 1].

Table 1:- Sample size calculation of the associated factors

\begin{tabular}{|llll|}
\hline Variables & Assumption & $\begin{array}{l}10 \% \text { Non-response } \\
\text { rate }\end{array}$ & $\begin{array}{c}\text { Sample } \\
\text { size }\end{array}$ \\
\hline $\begin{array}{l}\text { Food } \\
\text { security }\end{array}$ & $\begin{array}{l}\text { AOR }=5.3(2.5-8.3), \text { Power }=80 \% \text {, Ratio 1:3 P } \\
=9.2 \%\end{array}$ & 138 & 152 \\
\hline Occupation & $\begin{array}{l}\text { AOR }=1.4(0.8-2.3), \text { Power }=80 \% \text {, Ratio 3:1 } \\
40.2 \%\end{array}$ & 126 & 139 \\
\hline Tuberculosis & $\begin{array}{l}\text { AOR }=2.3(1.3-4.9), \text { Power }=80 \%, \text { Ratio 3:1 } \\
\mathrm{P}=39.7 \%\end{array}$ & 270 & 297 \\
\hline
\end{tabular}

\subsubsection{Sampling technique}

In Oromia special zone surrounding Finfinne zone, there were one primary Hospital and eight health centers providing ART service. One hospital and eight health centers were participated after which their respective sample was assigned proportionally as per their total adult PLWHA on ART visiting their ART clinic. List of eligible PLWHA were identified using their unique ART number. The actual study participants were selected using systematic sampling technique, which is calculated as: $-K=N / n, \quad 1449 / 305,=4.75$ $\sim 5$. Where; N: Total ART clients and $\mathrm{n}$ : calculated sample size. Accordingly, every $5^{\text {th }}$ participant was included in the study. The $1^{\text {st }}$ participant was selected by lottery method from the first one to five listed clients in each facility [Table 2].

Table 2:- Proportionate sample assigned of adult people on HAART per health center 


\begin{tabular}{|c|c|c|c|c|}
\hline S.no & Woreda/Town & $\begin{array}{l}\text { Health } \\
\text { Center }\end{array}$ & $\begin{array}{l}\text { Total number of HIV positive } \\
\text { adult people on HAART of each } \\
\text { Health center in, } 2020\end{array}$ & $\begin{array}{l}\text { Proportionally } \\
\text { sample assigned for } \\
\text { each health center. }\end{array}$ \\
\hline 1 & Sendafa town & $\begin{array}{l}\text { Sendafa } \\
\text { Health } \\
\text { Center }\end{array}$ & 442 & 93 \\
\hline 2 & Berrek & $\begin{array}{l}\text { Sire-goyo } \\
\text { Health } \\
\text { Center }\end{array}$ & 28 & 6 \\
\hline 3 & Mulo & $\begin{array}{l}\text { Hoja-dure } \\
\text { Health } \\
\text { Center }\end{array}$ & 75 & 16 \\
\hline \multirow[t]{2}{*}{4} & Sebbeta & $\begin{array}{l}\text { Awash } \\
\text { Health } \\
\text { Center }\end{array}$ & 72 & 15 \\
\hline & & $\begin{array}{l}\text { Tefki Health } \\
\text { Center }\end{array}$ & 98 & 21 \\
\hline 5 & Welmera & $\begin{array}{l}\text { Mennagasha } \\
\text { Kolobo } \\
\text { Health } \\
\text { Center }\end{array}$ & 153 & 32 \\
\hline \multirow[t]{2}{*}{6} & Sululta & $\begin{array}{l}\text { Chancho } \\
\text { Health } \\
\text { Center }\end{array}$ & 390 & 81 \\
\hline & & $\begin{array}{l}\text { Derba Health } \\
\text { Center }\end{array}$ & 27 & 6 \\
\hline 7 & $\begin{array}{l}\text { Chancho } \\
\text { Primary } \\
\text { Hospital }\end{array}$ & $\begin{array}{l}\text { Chancho } \\
\text { primary } \\
\text { Hospital }\end{array}$ & 164 & 34 \\
\hline Total & & & 1,449 & 304 \\
\hline
\end{tabular}

\subsection{Measurement}

\subsubsection{Variables}

Dependent variable

- Under nutrition 
Independent variables

- Socio-demographic factors:-Age, Sex, Marital status, Ethnicity, Educational status, Family size, Residence.

- Socio-economic factor:-Monthly income, Financial support, food aid.

- Health status related factors:-CD4 level, ART clinical stage, Months on ART.

- Food consumption, food insecurity, Frequency of consuming.

\subsection{Data collection instrument and procedures}

\subsubsection{Data collection Instrument}

The data were collected using structured questionnaire which was adopted from different literature and guidelines for measuring household and individual dietary diversity by Food and Agricultural Organization of United Nations (FAO). The questionnaire has three parts. The first part addresses sociodemographics and economic characteristics and dietary related items; the second part was about taking anthropometric measurements of the respondents while the third part was reviewing patient's card.

\subsubsection{Data collection procedures}

Five data collectors and one supervisor were recruited and trained for two days concerning the objective, standardizing the data collection instrument among the data collectors and providing them with basic skill of communicating with the study participants. The interview was taken place after taking the written consent from the respondents. A single interview took from 15-20 minutes.

\subsection{Data processing and analysis procedures}

Data cleaning and coding:-Data cleansing was undertaken after the data collected was entered. Questionnaires were checked for completeness and accuracy after each interview and before data entry. As all questionnaires filled completely, any falling data values outside of expected values were rechecked with original questionnaire and cleaned data were analyzed.

Data Analysis:-After the data were entered in to Epi-Data version 3.1, it was exported to SPSS version 24. Descriptive statistics was done to measure the prevalence of under nutrition and food insecurity in the study population. Bivariate analysis; binary logistic regression was employed to measure the strength, direction, association and significance of independent variables over dependent (under-weight and food insecurity) and multivariable analysis; was also employed to eliminate covariate expressed by Adjusted odd ratio (AOR) and $95 \% \mathrm{Cl}$ was used to measure direction, strength and significance of association at $\mathrm{P}$ value 0.05 . 


\subsection{Data Quality Management}

To assure the data quality different procedures were applied. The questionnaire was translated to Afaan Oromo and back to English by translators who were blind to the original questionnaire. The data collection instrument was tested prior to use for current study, on the one of adjacent woredas health facility providing ART service. Before starting data collection, the questionnaire was amended depending on the result of pretest. Final version of the questionnaire was used for data collection. And the interview was conducted in a separate room for privacy and confidentiality. Accuracy of anthropometric measurement was measured by evaluating the maximum standard difference in repeated measurements ( $0.5 \mathrm{~kg}$ for weight and $0.1 \mathrm{~cm}$ for height). Completeness and accuracy of the data were checked after interviewing each respondent by the data collectors and daily by the supervisors. Also completeness, accuracy and consistence were checked during data entry and analysis. Over all activity was monitored by the principal investigator for the data management issues.

\subsection{Operational Definition}

- Under-nutrition:-PLHIV on ART whose BMI is less than $18.5 \mathrm{Kg} / \mathrm{m}^{2}$ [25].

- Body mass index:-A statistical measure of the body based on weight, calculated by dividing weight in kilograms $(\mathrm{kg})$ by height in meters $(\mathrm{m})$ squared, or $\left(\mathrm{Kg} / \mathrm{m}^{2}\right)[26]$.

- Opportunistic infection:-An infection which takes advantage of weakness in immune system; people living with HIV are vulnerable to such opportunistic infections as tuberculosis, bacterial pneumonia, candidacies, herpes simplex and Kaposi sarcoma[27].

- Food Security:-Households and individuals need to have available food, access to food, and the ability to fully utilize it once it is consumed. A food secure household experiences none of the food insecurity (access) conditions, or just experiences worry, but rarely [28, 29, 30].

- Food insecurity:-A exists when people lack secure access to sufficient amounts of safe and nutritious food for normal growth and development and an active and healthy life, when the HFIAS is greater than or equal to $2[30,31]$.

- Dietary diversity:-is the number of reported different foods and food groups consumed by PLWHA within the last 24 hours[32].

- Non adherent:-When a PLWHA not able to take more than 95\% (missing at least one dose of all prescribed doses of ART) of the prescribed drug or failed to follow the schedule/time of the medication [19].

- Low Dietary diversity:-When PLWHA ate less than the mean dietary diversity score

- High dietary diversity:-When PLWHA ate greater than or equal to the mean dietary diversity score [32].

\subsection{Ethical considerations}


After the proposal was presented, ethical clearance was obtained from research and ethical committee institute of Health Sciences, Wollega University. The support letter was given to OSZSF zone health department, Woreda/town health office and the selected health facilities providing ART service within the zone for facilitation of data collection. The purpose of the study was introduced to all participants prior to interview and their willingness to participate or not to participate in the study without any preconditions was confirmed. They were also informed that code was used rather than name for confidentiality, informed written consent was obtained from all participants on the study.

\section{Result}

Out of the total 305 study participants, three hundred four (304) respondents participated in the study, making the response rate $99.7 \%$. The mean age of PLHIV and on ART was 39.9 (9.4SD) and $60.2 \%$ of them were in 34-49 years age group. Majority of the participants were 212(69.9\%) female. One hundred eleven (36.5\%) of the respondents were married. Out of the total participants, $210(72 \%)$ and $77(25.3 \%)$ were Oromo and Amara in ethnicity respectively, and also 249(81.9\%) of them were Orthodox Christian. Regarding, educational status majority of them $259(85.2 \%)$ were primary and less than, and $181(56.6 \%)$ were unemployed. One hundred eleven (36.5\%) clients were from house hold average monthly income $\leq$ 2250 Ethiopian Birr(ETB) background and 138(45.4), 80(26.3) of clients get money or other aids and ration from some organization respectively[Table 3].

Table 3:- Socio-demographic characteristics of PLWHA on HAART attending in public health facilities, Oromia Special Zone Surrounding Finfinne zone, Ethiopia 2021. 


\begin{tabular}{|c|c|c|}
\hline Socio-demographic characteristics variables & Frequency $(\mathrm{N})$ & Percentage (\%) \\
\hline \multicolumn{3}{|l|}{ Age(in years) } \\
\hline $18-33$ & 74 & 24.3 \\
\hline $34-49$ & 183 & 60.2 \\
\hline $50-65$ & 47 & 15.5 \\
\hline \multicolumn{3}{|l|}{ Sex } \\
\hline Male & 92 & 30.3 \\
\hline Female & 212 & 69.7 \\
\hline \multicolumn{3}{|l|}{ Marital status } \\
\hline Single & 31 & 10.2 \\
\hline Married & 111 & 36.5 \\
\hline Divorced & 96 & 31.6 \\
\hline Widowed & 66 & 21.7 \\
\hline \multicolumn{3}{|l|}{ Ethnicity } \\
\hline Oromo & 210 & 72 \\
\hline Amara & 77 & 25.3 \\
\hline Others & 8 & 2.7 \\
\hline \multicolumn{3}{|l|}{ Religion } \\
\hline Orthodox & 249 & 81.9 \\
\hline Protestant & 33 & 10.9 \\
\hline Others & 22 & 7.2 \\
\hline \multicolumn{3}{|l|}{ Literacy status } \\
\hline Primary and less & 259 & 85.2 \\
\hline Secondary and above & 45 & 14.8 \\
\hline \multicolumn{3}{|l|}{ Employment } \\
\hline Employed & 132 & 43.4 \\
\hline Unemployed & 172 & 56.6 \\
\hline \multicolumn{3}{|l|}{ Average $\mathrm{HH}$ income(in Ethiopian Birr, ETB) } \\
\hline$<=2250 \mathrm{~EB}$ & 223 & \\
\hline
\end{tabular}




\begin{tabular}{|c|c|c|}
\hline$>2250$ EB & 81 & \\
\hline \multicolumn{3}{|c|}{ Gets Ration support from some Organization from } \\
\hline Yes & 80 & 26.3 \\
\hline No & 224 & 73.7 \\
\hline \multicolumn{3}{|c|}{ Money or any aids from some Organization } \\
\hline Yes & 138 & 45.4 \\
\hline No & 166 & 54.6 \\
\hline
\end{tabular}

More than ninety percent; 280 of PLHIV on HAART attending public health facilities in OSZSF zone were stage one in WHO clinical staging and 206 (67.8\%) were with CD4 count greater or equal to 350, only $32.2 \%$ were less than 36 months since ART initiation. Regarding feeding pattern; 285(93.5\%) were ate three and above per day while very few $12(3.9 \%)$ consume low diversified diets (ate three and less types of food groups in 24hours) and 165(54.3\%) were from a household food in secure [Table 4].

Table 4:- Clinical characteristics of PLHIV on HAART attending in public health facilities, Oromia Special Zone Surrounding Finfinne zone, Ethiopia 2021. 


\begin{tabular}{|c|c|c|}
\hline Clinical characteristics variables & Frequency $(\mathrm{N})$ & Percentage (\%) \\
\hline \multicolumn{3}{|l|}{ WHO clinical stage } \\
\hline Stage 1 & 280 & 92.1 \\
\hline Stage 2- 4 & 24 & 7.9 \\
\hline \multicolumn{3}{|l|}{ Recent CD4 count } \\
\hline$<350$ & 98 & 32.2 \\
\hline$>=350$ & 206 & 67.8 \\
\hline \multicolumn{3}{|l|}{ Months on ART } \\
\hline$<=36$ month & 75 & 24.7 \\
\hline$>36$ month & 229 & 75.3 \\
\hline \multicolumn{3}{|l|}{ Frequency of feeding } \\
\hline$<=2$ per day & 19 & 6.2 \\
\hline$>=3$ per day & 285 & 93.8 \\
\hline \multicolumn{3}{|l|}{ Dietary Diversity } \\
\hline Low DD & 12 & 3.9 \\
\hline High DD & 292 & 94.1 \\
\hline \multicolumn{3}{|l|}{ Food In security } \\
\hline Secure & 139 & 45.7 \\
\hline In secure & 165 & 54.3 \\
\hline
\end{tabular}

As indicated on figure 2, two hundred seven (68.1\%) were had body mass index (BMI) $18.5-24.99 \mathrm{Kg} / \mathrm{m}^{2}$ (normal body weight) however, 36(11.8\%), 17(5.6\%) and 17(4.9\%) were had BMI 17-18.49 Kg/m² (mild underweight), BMI 16-16.99 Kg/m² (Moderate underweight) and BMl $16 \mathrm{~kg} / \mathrm{m}^{2}$ (Severe underweight) respectively. In the reverse; about 26(8.6\%) were had BMI $25-29.99 \mathrm{Kg} / \mathrm{m}^{2}$ (over weight) and only 3 respondents had $\mathrm{BMI}=\geq 30$ (Obesity) [Figure 2].

Figure 2:- Percentage distribution of nutritional status of PLWHA on HAART attending public health facility in OSZSF zone, Ethiopia 2021.

More than three fourth (79.9\%) of PLHIV on HAART attending public health facility in OSZSF zone ate three times per day and only $6.3 \%$ ate two times with 24 hour while the rest ate four and above times per day[Figure 3]. 
Figure 3:- Distribution of feeding frequency per day of PLWHA on HAART attending public health facility in OSZSF zone, Ethiopia 2021.

As shown in figure 4, majority of PLHIV on HAART attending in public health facility OSZSF zone ate Cereals (staple food) 279(91.8\%), Oils and fats 267 (87.8\%) and miscellaneous (Spices, condemns and beverage) $264(86.8 \%)$ and only $62(20.4 \%), 61(20.1 \%)$ were ate meat and eggs respectively. While fish and sea foods eaten rarely [Figure 4].

Figure 4:- Food groups ate by PLHIV on HAART and attending public health facility in OSZSF zone, Ethiopia 2021.

Nine point five percent of the study PLHIV on HAART attending public health facility in OSZSF zone were from severely household food in secure, while $73(24 \%)$ and $67(22 \%)$ were from moderately and mildly food in secured house hold respectively[Figure 5].

Figure 5:- Percentage distribution of house hold food in secure adult PLWHA on ART attending public health facility OSZSF zone, Ethiopia 2021.

Majority of PLHIV on HAART attending ART clinic limits portion of food 118 and reduces frequency of meal 112 for coping phased household food insecurity. Very low 4 respondents get money for food by having sex [Figure 6].

Figure 6: Distribution of coping mechanism used for food in security by Adult PLWHA on HAART attending public health facility in OSZSF zone, Ethiopia 2021.

Table 5:- Nutritional status of PLWHA on ART attending public health facilities, in Oromia Special Zone Surrounding Finfinne zone, Ethiopia, 2021. 


\begin{tabular}{|c|c|c|c|c|}
\hline \multirow[t]{2}{*}{ variables } & \multicolumn{2}{|c|}{ Under nutrition } & \multirow[t]{2}{*}{$x^{2}$} & \multirow[t]{2}{*}{ P-value } \\
\hline & Yes & No & & \\
\hline \multicolumn{5}{|l|}{ Age } \\
\hline $18-33$ & $19(25.7)$ & $55(74.3)$ & .68 & .66 \\
\hline $34-49$ & $38(20.8)$ & $145(79.2)$ & & \\
\hline $50-65$ & $11(25.5)$ & $36(74.5)$ & & \\
\hline \multicolumn{5}{|l|}{ Sex } \\
\hline Male & $23(25)$ & $69(75)$ & .46 & .46 \\
\hline Female & $45(21.2)$ & 167(78.8) & & \\
\hline \multicolumn{5}{|l|}{ Marital status } \\
\hline Single & $8(25.8)$ & $23(74.2)$ & .855 & 0.77 \\
\hline Married & $22(19.8)$ & $89(80.2)$ & & \\
\hline Divorced & $22(22.9)$ & 74(77.1) & & \\
\hline Widowed & $16(24.6)$ & $50(75.4)$ & & \\
\hline \multicolumn{5}{|l|}{ Literacy status } \\
\hline Primary and less than & $60(23.2)$ & 199(76.8) & 0.42 & 0.42 \\
\hline Secondary and above & $8(17.8)$ & $37(82.2)$ & 1 & \\
\hline \multicolumn{5}{|l|}{ Family Size } \\
\hline$\leq 2$ & $34(26.6)$ & $85(71.4)$ & & \\
\hline$\geq 3$ & $34(18.4)$ & 151(81.6) & .034 & .039 \\
\hline \multicolumn{5}{|l|}{ Employment } \\
\hline Employed & $30(22.7)$ & 102(77.3) & & \\
\hline Unemployed & $38(22.1)$ & 134(77.9) & 0.89 & .89 \\
\hline \multicolumn{5}{|l|}{ Income } \\
\hline Yes & $23(11.6)$ & $176(88.4)$ & & \\
\hline No & $45(42.9)$ & $60(57.1)$ & .17 & .17 \\
\hline \multicolumn{5}{|l|}{ Average $\mathrm{HH}$ income } \\
\hline$<=2250 \mathrm{~EB}$ & $49(22)$ & 174(78) & 0.78 & .78 \\
\hline
\end{tabular}


Gets ration support from some Organization

from

Yes

No

Money or any aids from some Organization

Yes

No

WHO clinical stage

Stage 1

Stage 2- 4

Recent CD4 count

$<=350$

$>350$

Months on ART

$<=36$ month

$>36$ month

Frequency of feeding

$<=3$ per day

$>3$ per day

Dietary Diversity

Low DD

High DD

Food security

Secure

In secure
12(14.5) $\quad 71(85.5)$

56(25.3) 165(74.7)

$.043 \quad .045$
30(15) 170(85)

$\begin{array}{llll}42(40.4) & 62(59,6) & 0.56 & 0.56\end{array}$
52(18.6) $228(81.4)$

16(66.7) 8(33.3)

0.001

$\begin{array}{llll}31(31.6 \%) & 67(68.4) \quad 008 \quad .008\end{array}$

37(24.6) $\quad 169(75.4)$

18(24) 57(76)

50(22.3) 174(77.7)

$.69 \quad .69$

$\begin{array}{llll}8(42.1) & 11(57.9) & 0.033 & .039 \\ 60(21.1) & 225(78.9) & & \end{array}$

6(50)

$6(50)$

.019

.028

62(21.2) 230(78.8)

23(16.5) 116(83.5)

45(27.3) 120(72.7)

.025

.027

In the current study the prevalence of under nutrition was $68(22.4 \%)$. Out of this $45(66.2 \%)$ were female and $60(88.2 \%)$ of them were primary and less in literacy status. Half of undernourished respondents were from a family member of 3 and above were associated with under nutrition $(\mathrm{COR}=0.56,95 \mathrm{Cl}=0.32$ - 
0.97) and forty five (66.2\%) of clients had not their own monthly income similarly $49(22 \%)$ were from average household monthly income less than 2250 EB. Regarding, access to aids 31(45.6\%) able to get money and others aids from some organization however, only $12(17.6 \%)$ were access to food ration from some organization [Table 6].

Table 6:- Factors associated with HIV/AIDS clients attending antiretroviral therapy in public health facilities, Oromia Special Zone Surrounding Finfinne, Ethiopia, 2021. 
variables

Male

Female

Marital Status

$$
\text { Single }
$$

Married

Divorced

Widowed

Literacy status

Literate

Illiterate

\section{Family Size}

$\begin{array}{lllll}\leq 2 & 34(26.6) & 85(71.4) & \begin{array}{l}.56(0.32- \\ 0.97)^{*}\end{array} & \begin{array}{l}0.75(0.41- \\ 1.36)\end{array} \\ \mathbf{2 3} & 34(18.4) & 151(81.6) & 1\end{array}$

Income

$$
\text { Yes }
$$

No

Average $\mathrm{HH}$ income

$$
\begin{aligned}
& <=2250 \text { ETB } \\
& >2250 \text { ETB }
\end{aligned}
$$

Gets Ration support from some Organization from

$$
\begin{aligned}
& \text { Yes } \\
& \text { No }
\end{aligned}
$$

Under nutrition

$\operatorname{COR}(95 \% \mathrm{Cl})$

Yes No
$45(21.2) \quad 167(78.8)$
$\mathrm{AOR}(95 \% \mathrm{Cl})$ 


\begin{tabular}{|llll|}
\hline Yes & $31(20.7)$ & $119(79.3)$ & 1 \\
\hline No & $37(24)$ & $117(76)$ & $1.17(0.68-2)$ \\
\hline
\end{tabular}

\subsection{Factors association with under nutrition and food in secure among clients on ART}

To identify the association between the independent or predictor variables and dependent (under nutrition BMl<18.5), both bivariate and multivariable logistic regression were used. After entering all variables in to binary logistic regression; family size, individual monthly income, average house hold monthly income, presence of ration food from some organization, frequency of feeding, diet diversity score, food security status, CD4 count, and WHO clinical stage were significantly associated with under nutrition at $p$-value $=0.25$. Similarly, Occupational status, literacy status, individual income households income, accessibility to ration foods, accessibility to money and other aids and feeding frequency were significantly associated to food insecurity. After controlling the confounding factors, in a multivariable logistic analysis, access to ration foods from some Organization, food security status and WHO clinical stage were significantly associated with under nutrition at p-value less than 0.05 . And literacy, employment and feeding frequency exist associated significantly with food in security.

Clients who were access to ration foods from some Organization were by $58 \%$ less likely to get under nutrition than those who didn't get ration. The odds of PLWHA on HAART attending public health facility in OSZSF zone being WHO clinical stage two, three and four were 6.4 times more likely to be undernourished when compared with those who were stage one in $\mathrm{WHO}$ clinical staging. Concerning the house hold food security status, being from a house hold food secured were $49 \%$ less likely to develop under nutrition than those who were from in secured background. The odds of being primary and less in educational level were two folds more likely to be from food in secured house hold when compared with those who were with secondary and above educational status. Being from a household average income $>2250$ ETB were (AOR=0.41, 95\% Cl: 0.21-0.8) less likely being from household food in secured. Client those who ate two and less than two within $24 \mathrm{hr}$ were 4.1 times ( $\mathrm{AOR}=4.1,95 \% \mathrm{Cl}: 1.3-13.46)$ to be a member of food in secure house hold than those who ate three and above meal per day [Table 7, Table 8].

Table 7:- Factors associated with under nutrition among on HIV/AIDS clients attending antiretroviral therapy in public health facilities, Oromia Special Zone Surrounding Finfinne zone, Ethiopia, 2021. 


\begin{tabular}{|c|c|c|c|c|}
\hline \multirow[t]{2}{*}{ Variable } & \multicolumn{2}{|c|}{ Under nutrition } & \multirow[t]{2}{*}{$\operatorname{coR}(95 \% \mathrm{Cl})$} & \multirow{2}{*}{$\begin{array}{l}\text { AOR(95\%Cl) } \\
\text { Yes }\end{array}$} \\
\hline & Yes & No & & \\
\hline \multicolumn{5}{|l|}{ WHO clinical stage } \\
\hline Stage 1 & $52(18.6)$ & $228(81.4)$ & 1 & 1 \\
\hline Stage 2-4 & $16(66.7)$ & $8(33.3)$ & $.11(.046-0.26)^{*}$ & $6.8(2.5-18.6)^{\star \star}$ \\
\hline \multicolumn{5}{|l|}{ Recent CD4 count } \\
\hline$<350$ & $31(31.6 \%)$ & $67(68.4)$ & $2.1(1.2-3.6)^{\star}$ & $0.8(0.4-1.4)$ \\
\hline$>=350$ & $37(24.6)$ & $169(75.4)$ & 1 & \\
\hline \multicolumn{5}{|l|}{ Months on ART } \\
\hline$<=36$ month & $18(24)$ & $57(76)$ & $1.13(0.6-2.09)$ & \\
\hline$>36$ month & $50(22.3)$ & 174(77.7) & 1 & \\
\hline \multicolumn{5}{|l|}{ Frequency of feeding } \\
\hline$<=3$ per day & $8(42.1)$ & 11(57.9) & & \\
\hline$>3$ per day & $60(21.1)$ & $225(78.9)$ & $0.9(0.4-2.1)$ & \\
\hline \multicolumn{5}{|l|}{ Dietary Diversity } \\
\hline Low DD & $6(50)$ & $6(50)$ & $3.7(1.1-11.9)^{\star}$ & $0.39(0.09-1.57)$ \\
\hline High DD & $62(21.2)$ & $230(78.8)$ & 1 & \\
\hline \multicolumn{5}{|l|}{ Food security } \\
\hline Secure & $23(16.5)$ & $116(83.5)$ & 1 & \\
\hline In secure & $45(27.3)$ & $120(72.7)$ & $0.5(0.3-0.9) *$ & $0.51(0.27-0.95)^{\star \star}$ \\
\hline
\end{tabular}

Table 8:- Factors associated with food insecurity among HIV/AIDS clients on HAART attending in public health facilities, OSZSF zone, Ethiopia, 2021. 
Variables

Male

Female

Employment

Employed

Unemployed

Literacy status

Primary and less

Secondary \& above

Income

Yes

No

Average $\mathrm{HH}$ income

$$
\begin{aligned}
& <=2250 \text { ETB } \\
& >2250 \text { ETB }
\end{aligned}
$$

Gets ration support from some

Organization from

$$
\text { Yes }
$$

No

Money or any aids from some Organization

$$
\begin{aligned}
& \text { Yes } \\
& \text { No }
\end{aligned}
$$

Frequency of feeding

$<=2$ per day

$>=3$ per day
Food insecure

$\operatorname{COR}(95 \% \mathrm{Cl})$

$\operatorname{AOR}(95 \% \mathrm{Cl})$

Yes No

45(48.9) 47(51.1) 1

$120(56.6) \quad 92(43.4) \quad 1.4(0.8-2.2)$

63(47.7) 69(52.3) 1

102(59.3) $70(40.1) \quad 1.6(1-2.52)$ *

$15(33.3) \quad 30(66.7) \quad 1$

$0.36(0.19-\quad 2.24(1.1-$

$\left.07)^{*} \quad 4.6\right)^{\star \star}$

105(49.8) 106(50.2) 1

60(60.6) 33(33.4) .54(0.33-

$0.9)^{*}$

1
$54(0.33$
$0.9)^{\star}$




\section{Discussion}

The overall magnitude of under nutrition in this study was $68(22.4 \%)$, out of this $15(4.9 \%), 17(5.6 \%)$ and $36(11.8 \%)$ were severely, moderately and mildly undernourished respectively. This is comparable with studies done in Ethiopia [9, 33, 24] and higher than the studies in Kathmandu Valey Nepal 19.2\% [34], Senegal Dakar 19.2\%, PASADA hospital 19.4\% [35] and Addis Abeba 16.5\% [36] . This difference is due to socioeconomic status of the study participant. But, the current studies finding is lower than the studies in Senegal Ziguichor 26.3\% [37], Hossaina town 31.2\% [38], Buttajira town 25.5\% [10], Wolayitta Soddo 26.6\% [39] and Jimma town 43\% [22] this difference might be due to difference in prevalence of HIV high in urban that affects nutritional status, level of awareness on HIV/AIDS interaction with nutrition and socioeconomic characteristics of the study participants. The prevalence of undernutrition in this study is higher among males $(25 \%)$ than female $(21.5 \%)$ but on the study done in west Shewa zone inversely higher among females (28\%) than males (18.7\%) while higher among widowed than married in both study $24.6 \%$ and $19.8 \%$ in current study, $33.3 \%$ and $21.9 \%$ in west Shewa zone[24].

Out of the total 68 undernourished PLHIV on ART and attending public health facility in OSZSF zone, $45(27.3 \%)$ were from a house hold food unsecured family members. In this study, the magnitude of household food insecure were 165(54.3\%); (Mild 9\%, Moderate 24\% and Severe 22\% food in secure) which is comparable with the study done in Kenbata Tenbaro zone $57.3 \%$ (Mild 13.3\%, Moderate $26.6 \%$ and Severe $17.4 \%$ food in secure)[11]. However, relatively it was very lower than other studies done in Senegal Dakar 84.6\% [40], Democratic Republic of Congo 91.3\% [41] and Fitche General Hospital 87.4\% [12]. The deference may be due to socio-economic status of study participants, study period that affects accessibility and availability of foods that leads in to absence of preferred food groups and level of health facilities they attend. Clients attending hospital are those who had advanced HIV/AIDS disease than the primary care unit attendants that leads them less productive and phase problem in securing food.

This study reveals that house hold food insecurity is one among significantly associated factors with undernutrition. Clients from house hold food secure were $61 \%$ less likely to develop undernutrition than those who were from house hold food insecure background. This is in line with other study in Ethiopia [24]. There were also other factors significantly associated with undernutrition; PLHIV on ART attending health facilities in OSZSF zone those who were different from WHO clinical stage one were 6.8 more likely develop under nutrition than those who were WHO clinical stage one. Similar studies verify this in Nepal[34], in Tanzania[35], and in Ethiopia[36,24] and in presence of food ration support from some organization; those who gets food ration support were $58 \%$ less likely to develop under nutrition than the counterpart. Whereas, $\mathrm{CD} 4$ count $(\mathrm{COR}=2.1,95 \% \mathrm{Cl}: 1.2-3.6)$, family size $(\mathrm{COR}=0.56,95 \% \mathrm{Cl}: 0.32-0.97)$ and diet diversity score $(\mathrm{COR}=3.7,95 \% \mathrm{Cl}: 1.1-11.9)$ were significantly associated with undernutrition independently. 
The odds of literacy status primary and less participants being from household food unsecured were 2.24 times higher than the counterpart (secondary and above educational status individuals). This is comparable with the study done in Nepal [34], and in Ethiopia [12]. Regarding average household monthly income among PLHIV on ART attending health facilities in OSZSF zone, those who were from household monthly income greater than 2250 ETB were less likely being from household food in secure by $59 \%$ than those who were from household average monthly income less than 2250 ETB. Similar study in Jimma zone recognizes this finding [24]. This may be due to PLHIV were had additional cost for medical care, time for production and less production due to morbidity. All these shares costs of foods for consumption that reduces types and amount of foods consumed.

\section{Conclusion And Recommendations 5.1. Conclusion}

This study identifies the magnitude of undernutrition on adult PLWHA on HAART was $22.4 \%$. Of this $11.8 \%, 5.6 \%$ and $4.9 \%$ were mildly, moderately and severely malnourished. Factors significantly associated with undernutrition were presence of ration food support from some organization, WHO clinical stage and household food insecurity. There was also high prevalence (54.3\%) of household food insecure and severe food insecure (9.5\%) identified. Participants' literacy status, feeding frequency per day and household average monthly income were factors associated with food insecurity significantly among adult PLWHA on HAART. This indicates that under nutrition and food insecurity has enormous implication on adult PLHIV and on ART.

\subsection{Recommendation}

As this study result states; there were complex interaction between food insecurity, undernutrition and HIV/AIDS. Thus, the following assumptions were proposed for intervention to alleviate the problems stated in this study.

- Comprehensive and integrative bio-medical service should be provided at health facility level that recognizes care and support (like income generating activities, foods support, and educational support). Inter-sectorial collaboration to increase coverage of education, create job opportunities and to ensure the household food security.

\section{Lists Of Acronyms And Abbreviation}

- AIDS ...Acquired Immune Deficiency Syndrome

- ART...Anti-retroviral therapy

- ARV...Anti-retroviral

- BMI...Body mass index 
- CD4...Cluster of differentiation

- HAART....Highly active anti-retroviral therapy

- HIV...Human immunodeficiency virus

- Kg...Kilogram

- OSZSF...Oromia special zone Surrounding Finfinne

- PLHIV...Peoples Living with Human immune virus

- PLWHA...Peoples living with HIV/AIDS

- WHO...World Health Organization

\section{Declarations}

\section{Acknowledgements}

We are grateful to all staff of Wollega University Institute of Health Science School of Public Health, and Oromia special zone surrounding Finfinne health department for their valuable contribution and unreserved cooperation in providing basic information about the health institution during the study. We also extend our thanks to data collectors, respondents, and supervisors for their cooperation during the study.

\section{Ethics approval and consent to participate}

Ethical clearance was obtained from research and ethical committee institute of Health Sciences, Wollega University. The support letter was given to OSZSF zone health department, Woreda or town health office and the selected health facilities providing ART service within the zone for facilitation of data collection. The purpose of the study was introduced to all study participants prior to interview and their willingness to participate or not to participate in the study without any preconditions was confirmed. They were also informed that code was used rather than name for confidentiality, informed written consent was obtained from all participants on the study.

\section{Consent for publication}

'Not applicable'

\section{Availability of data and materials}

The finding of this study was generated from the data collected and analyzed based on stated methods and materials. The original data supporting this finding are available from the corresponding author on reasonable request.

\section{Competing interests}

"The authors declare that they have no competing interests" 


\section{Funding}

'Not applicable'

\section{Authors' contributions}

DN participated in the design of the study, performed the data collection and the statistical analysis and served as the corresponding author of the manuscript. HB, TT, MD and ZK supervised the study, ensured quality of the data, assisted in the analysis and interpretation of the data. All authors read and approved the manuscript.

\section{Authors' information}

- DN is HIV Case Detection Officer, at Sandafa Health Center, Sandafa Town, Oromiya Region Centeral Ethiopia.

- HB is Lecturer at Wollega University department of Public Health, Institute of Health Science, Nekemte, Western Ethiopia.

- TT is Lecturer at Wollega University department of Public Health, Institute of Health Science, Nekemte, Western Ethiopia.

- MD is Lecturer at Wollega University department of Public Health, Institute of Health Science, Nekemte, Western Ethiopia.

- ZK is Water, Sanitation, Hygiene (WASH) and Neglected Tropical Diseases (NTDs) Program Coordinator, Nekemte town, Western Ethiopia.

\section{References}

1. Ministry of Health U. Comprehensive Nutrition Care for People Living with HIV, A Trainers Manual for Facility-Based Health Providers [Internet]. Available from: http://www.urc-

chs.com/sites/default/files/Comprehensive Nutrition Care for People Living with HIV-AIDS.pdf.

2. Summary E. Global Nutrition Report. 2018.

3. Hadgu TH, Worku W, Tetemke D, Berhe H. Undernutrition among HIV positive women in Humera hospital, Tigray, Ethiopia, 2013: Antiretroviral therapy alone is not enough, cross sectional study. BMC Public Health. 2013;13(1):1-10.

4. FAO, IFAD, UNICEF, WFP, WHO. Food Security and Nutrition in the World the State of Building Climate Resilience for Food Security and Nutrition [Internet]. 2018. Available from: www.fao.org/publications

5. Ivers LC, Cullen KA, Freedberg KA, Block S, Webb P. NIH Public Access. 2010;49(7):1096-102.

6. Food Insecurity-Nutrition, Metabolism \& GI Research in HIV-CFAR Nutrition Core.

7. Res JAC, Zekeri AA. AIDS \& Clinical Research Food Insecurity and Coping Strategies among African American Women Living with HIV / AIDS on Antiretroviral Therapy in Rural Alabama. 2016;7(6).

8. The Nutrition Challenge in Sub-Saharan Africa. 2012;(January). 
9. Saliya MS, Azale T, Alamirrew A, Tesfaye DJ. by human immune deficiency virus on antiretroviral therapy: A cross sectional study in Siltie e ci al $m$ er on $m$ er on om ci. 2018;6.

10. Gedle D. Food Insecurity and its Associated Factors among People Living with HIV/AIDS Receiving Anti-Retroviral Therapy at Butajira Hospital, Southern Ethiopia. J Nutr Food Sci. 2015;05(02):2-7.

11. Markos M, Egata G, Dessie Y. East African Journal of Health and Biomedical Sciences ( 2018 ) Food Insecurity and Associated Factors among Adult HIV Positives Attending Antiretroviral Therapy in Public Health Facilities of Kembata Tembaro Zone, Southern Ethiopia. 2018;2:23-34.

12. Tolasa B. Food Insecurity and Associated Factors among People Living with HIV Attending ART Clinic in Fitche Zonal Hospital , Ethiopia. 2015;8(3):8-17.

13. Baym N. 1. Introduction. Nov Readers, Rev. 2019;13-25.

14. Safety F. Living with HIV HIV and Nutrition and Food Safety. 2018;2-5.

15. Frega R, Duffy F, Rawat R, Grede N. Food insecurity in the context of HIV/AIDS: A framework for a new era of programming. Food Nutr Bull. 2010;31(4).

16. Rajabiun S. HIV/AIDS: A Guide For Nutrition, Care and Support July 2001. Nutrition. 2001;(July).

17. Coleman-jensen A, Rabbitt MP, Gregory CA, Coleman-jensen A, Rabbitt MP, Gregory CA, et al. Household Food Security in the United States in 2017, ERR-256. United States Dep Agric. 2018; (September).

18. De Pee S, Semba RD. Role of nutrition in HIV infection: Review of evidence for more effective programming in resource-limited settings. Vol. 31, Food and Nutrition Bulletin. 2010. 1990-2006 p.

19. Federal Minstry of, Health. National Guidelunes for comprehensive HIV Prevention, Care and Treatment. 2017;1.226.

20. Alebel A, Kibret GD, Petrucka P, Tesema C, Moges NA, Wagnew F, et al. Undernutrition among Ethiopian adults living with HIV: a meta-analysis. 2020;1-10.

21. Zemede Z, Tariku B, Kote M, Estifanos W. Undernutrition and associated factors among HIV-positive adult patients enrolled in antiretroviral therapy (ART) clinics in the arba minch area, southern Ethiopia. HIV/AIDS - Res Palliat Care. 2019;11:147-54.

22. Ab G, Ae G, Db K, Gizaw AB, Eshetu A, Birhanu D. General Medicine: Open Access Malnutrition and Associated Factors among Adult People Living with HIV / AIDS Receiving Antiretroviral Therapy at Organization for Social Service Health Development in Jimma Town Oromia Region South West. 2018;6(2):4-11.

23. Weiser S. Food Insecurity: Implications for ART Adherence and HIV Health Outcomes. 2014.

24. Gebremichael DY, Hadush KT, Kebede EM, Zegeye RT. Food insecurity, nutritional status, and factors associated with malnutrition among people living with HIV/AIDS attending antiretroviral therapy at public health facilities in West Shewa Zone, Central Ethiopia. Biomed Res Int. 2018;2018.

25. Tumilowicz A. Food and Nutrition Services among Adolescents and Adults Living with HIV. 2010; (March):1-14. Available from: www.fantaproject.org.

26. World Bank. and Food Security: What We Can Do. 2007. 
27. Zambia Ministry of Health F. Nutrition Guidelines For Care And Support Of People With HIV. 2017.

28. FAO, IFAD, UNICEF, WFP, WHO. Food Security and Nutrition in the World 2019. The state of food security and nutrition in the world. Safeguiarding against Economic Slowdowns and Downturns. 2019.

29. Coates, J., Swindale, A., Bilinsky P. HFIAS for Measurement of Food Access Indicator Guide. J Chem Inf Model. 2013;53(9):1689-99.

30. V GA, Zeller M. Use of household food insecurity scales for assessing poverty in Bangladesh and Uganda Pro-poor development in low income countries: Food, agriculture, trade, and environment Use of household food insecurity scales for assessing poverty in. 2007;(October):1-19.

31. Napoli M, Muro PP De, Mazziotta PM. Towards a Food Insecurity Multidimensional Index ( FIMI). 2011;1-72.

32. Vhurumuku E. Food security indicators. Food Agric Organ. 2014;(February):1-2.

33. Mitiku A, Ayele TA, Assefa M, Tariku A. Undernutrition and associated factors among adults living with Human Immune Deficiency Virus in Dembia District, northwest Ethiopia: An institution based cross-sectional study. Arch Public Heal [Internet]. 2016;74(1):1. Available from: http://dx.doi.org/10.1186/s13690-016-0143-y

34. Thapa R, Amatya A, Pahari DP, Bam K, Newman MS. Nutritional status and its association with quality of life among people living with HIV attending public anti-retroviral therapy sites of Kathmandu Valley, Nepal. AIDS Res Ther [Internet]. 2015;12(1):1-10. Available from: ???

35. Kabalimu TK, Sungwa E, Lwabukuna WC. Malnutrition and associated factors among adults starting on antiretroviral therapy at PASADA Hospital in Temeke District, Tanzania. 2018;20(2).

36. Asnakew M, Hailu C, Jarso H. Malnutrition and Associated Factors among Adult Individuals Receiving Highly Active Antiretroviral Therapy in Health Facilities of Hosanna Town, Southern Ethiopia. OALib. 2015;02(01):1-12.

37. Frega R, Duffy F, Rawat R, Grede N. Food insecurity in the context of HIV/AIDS: A framework for a new era of programming. Food Nutr Bull. 2010;31(4):292-312.

38. Bader $\mathrm{E}$, \& Claude M. Operationalizing dietary diversity assessment in the context of monitoring and evaluation of the Mali PASA 5 food security. Eur Comm. 2014;(July):1-55.

39. Lula A, Tsegaye $D$, Yoseph $\mathrm{H}$. Under nutrition and associated factors among adult on highly active antiretroviral therapy in Wolaita Sodo teaching and referral hospital, southern nations nationalities peoples region, Ethiopia. Int J Nutr Metab. 2017;9(2):10-9.

40. Benzekri NA, Sambou J, Diaw B, Sall EHI, Sall F, Niang A, et al. High prevalence of severe food insecurity and malnutrition among HIV-infected adults in Senegal, West Africa. PLoS One. 2015;10(11):1-17.

41. Akilimali PZ. Food insecurity and undernutrition in treated HIV patients a (post-) conflict setting: A cross sectional study from Goma, Eastern Democratic Republic of Congo. J Nutr Heal Food Sci. 2016;4(2):1-9. 
Figures

\section{Conceptual framework}

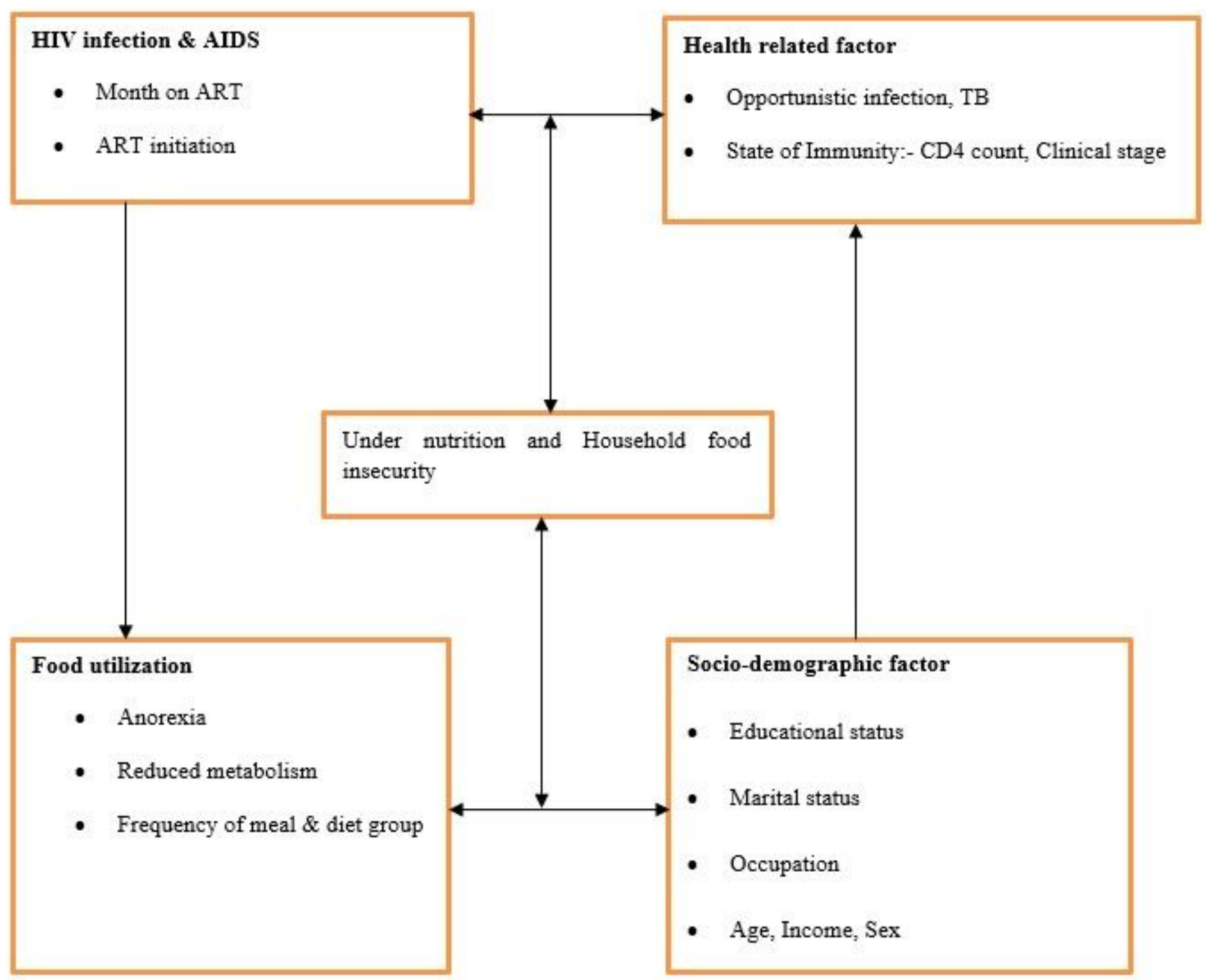

\section{Figure 1}

Conceptual Framework on food insecurity, under-nutrition and associated factors among PLWHIV on ART follow-up. 


\section{Percent}

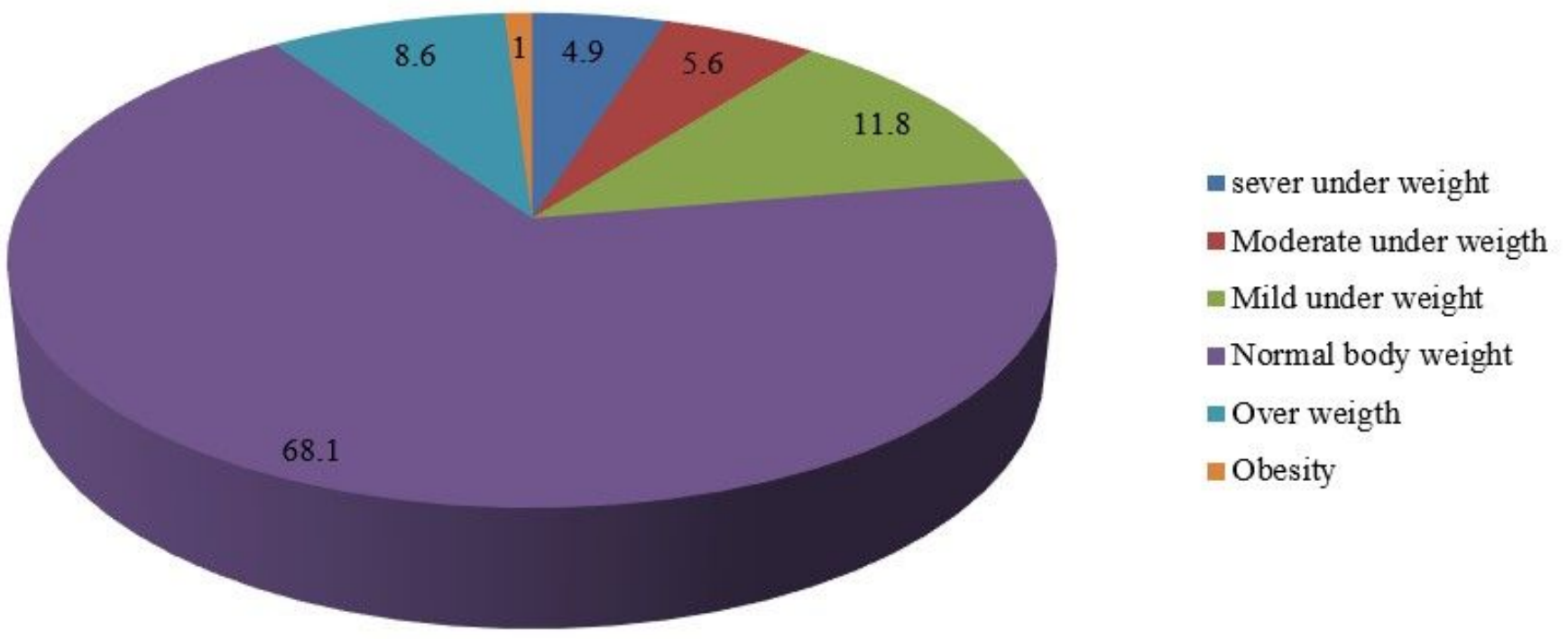

Figure 2

Percentage distribution of nutritional status of PLWHA on HAART attending public health facility in OSZSF zone, Ethiopia 2021.

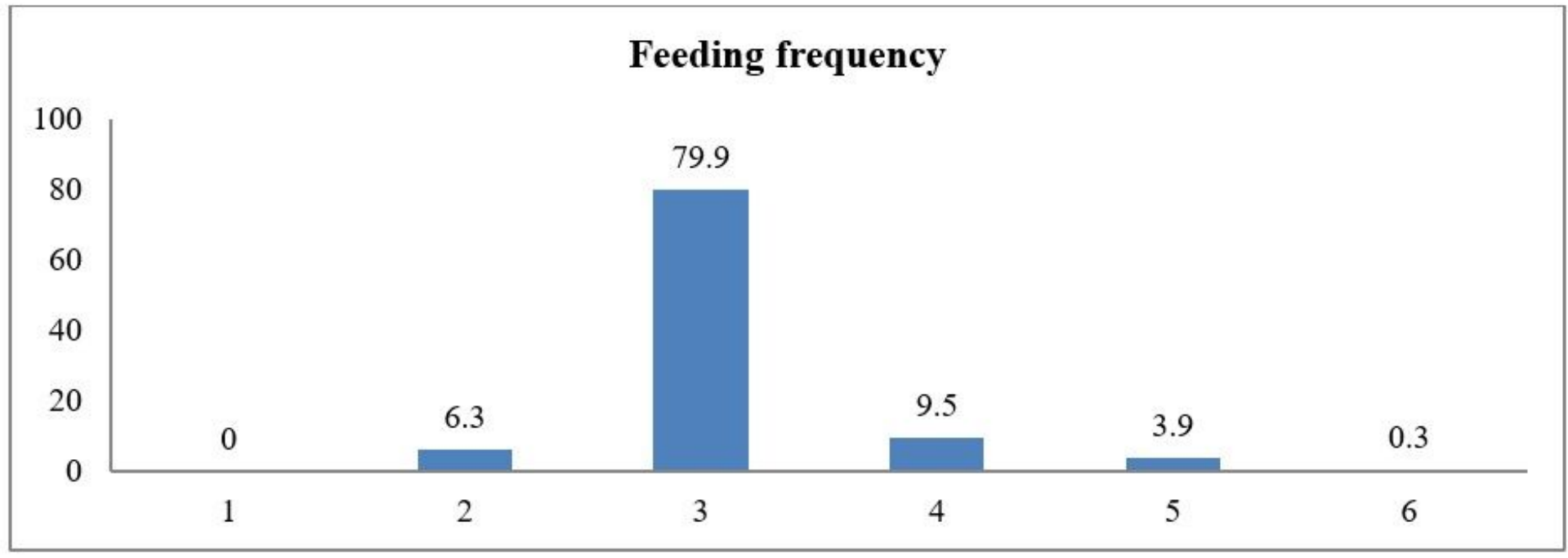

\section{Figure 3}

Distribution of feeding frequency per day of PLWHA on HAART attending public health facility in OSZSF zone, Ethiopia 2021. 


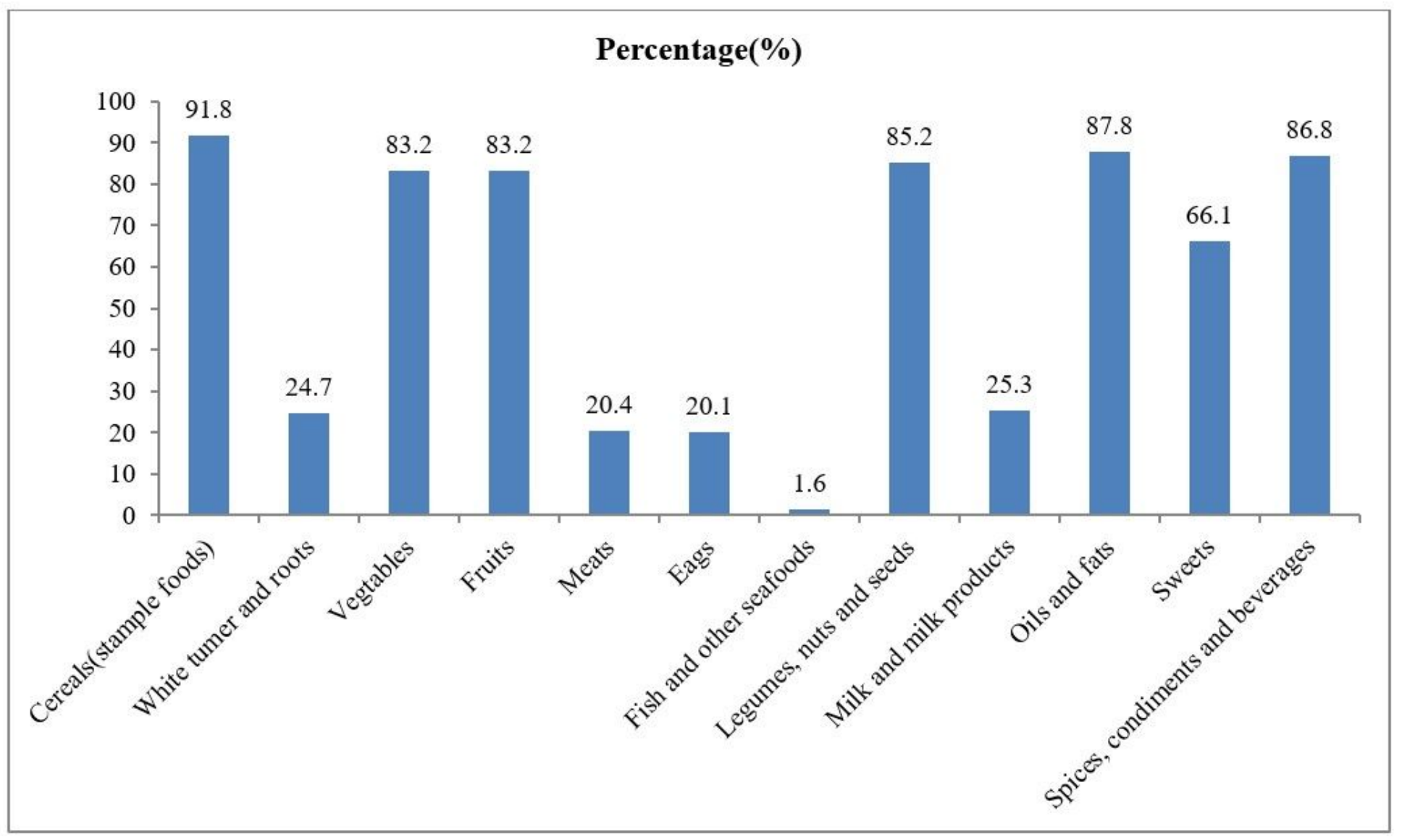

Figure 4

Food groups ate by PLHIV on HAART and attending public health facility in OSZSF zone, Ethiopia 2021.

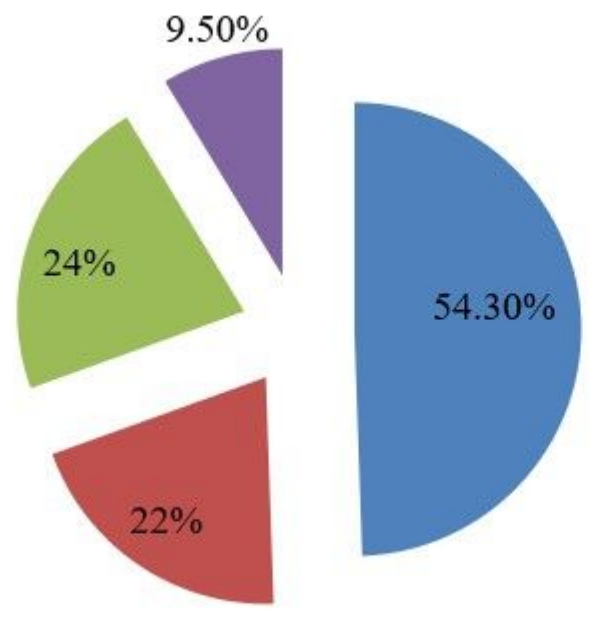

- Total insecure

mild in secure

moderate in secure

nevere in secure

Figure 5

Percentage distribution of house hold food in secure adult PLWHA on ART attending public health facility OSZSF zone, Ethiopia 2021. 


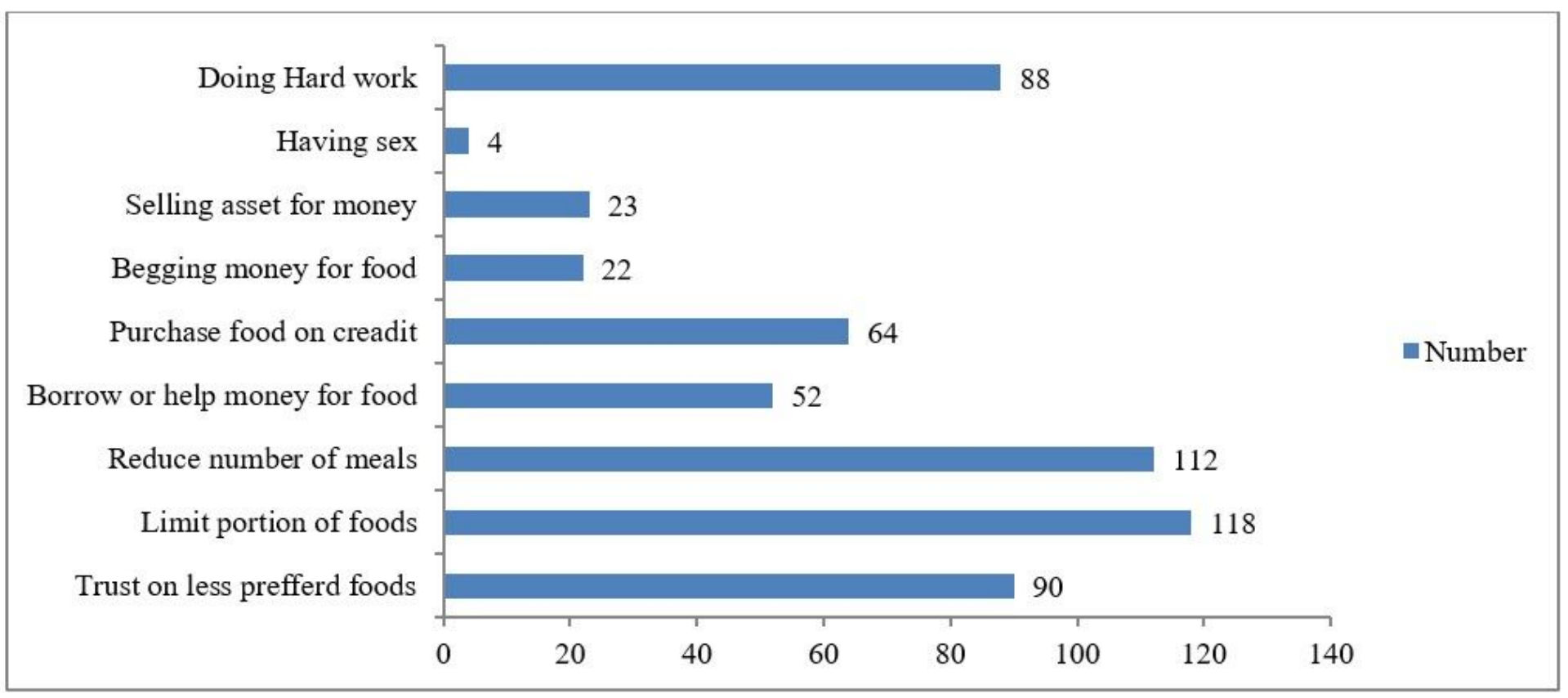

\section{Figure 6}

Distribution of coping mechanism used for food in security by Adult PLWHA on HAART attending public health facility in OSZSF zone, Ethiopia 2021.

\section{Supplementary Files}

This is a list of supplementary files associated with this preprint. Click to download.

- S1Annex.EnglishVersionStudyQuestionnaire.docx 